\section{Kidney \\ Blood Pressure Research}

\title{
Characterization and Activation of NLRP3 Inflammasomes in the Renal Medulla in Mice
}

\author{
Min Xia ${ }^{a} \quad$ Justine M. Abais ${ }^{a} \quad$ Saisudha Koka ${ }^{a} \quad$ Nan Meng ${ }^{a} \quad$ Todd W. Gehr \\ Krishna M. Boinia ${ }^{a, b}$ Pin-Lan Lia \\ ${ }^{a}$ Department of Pharmacology \& Toxicology, ${ }^{\text {DD }}$ ivision of Nephrology, School of Medicine, Virginia \\ Commonwealth University, Richmond, VA, USA
}

\section{Key Words}

Cellular inflammation $\bullet$ Renal medulla $\bullet$ Urinary excretion $\bullet$ Uric acid $\bullet$ Inflammatory mediators

\begin{abstract}
Background/Aims: Recent studies have indicated that local inflammatory mediators are importantly involved in the regulation of renal function. However, it remains unknown how such local inflammation is triggered intracellularly in the kidney. The present study was designed to characterize the inflammasome centered by NIrp3 in the kidney and also test the effect of its activation in the renal medulla. Methods and Results: By immunohistochemistry analysis, we found that inflammasome components, NIrp3, Asc and caspase-1, were ubiquitously distributed in different kidney areas. The caspase- 1 activity and IL-1 $1 \beta$ production were particularly high in the renal outer medulla compared to other kidney regions. Further confocal microscopy and RT-PCR analysis showed that NIrp3, Asc and caspase-1 were particularly enriched in the thick ascending limb of Henle's loop. In anesthetized mice, medullary infusion of Nlrp3 inflammasome activator, monosodium urate (MSU), induced significant decreases in sodium excretion and medullary blood flow without changes in mean arterial blood pressure and renal cortical blood flow. Caspase-1 inhibitor, Ac-YVAD-CMK and deletion of Nlrp3 or Asc gene abolished MSU-induced decreases in renal sodium excretion and MBF. Conclusion: Our results indicate that renal medullary Nlrp3 inflammasomes represent a new regulatory mechanism of renal MBF and sodium excretion which may not depend on classical inflammatory response.

\section{Introduction}

The Nlrp3 inflammasome is a well identified cytosolic protein complex that contains Nlrp3 (nucleotide-binding oligomerization domain, leucine-rich repeat and pyrin domain containing 3) proteins, ASC (apoptosis-associated speck-like protein containing a caspase 


\section{Kidney Blood Pressure Research}

Kidney Blood Press Res 2016;41:208-221

DOI: 10.1159/000443424

Published online: March 25, 2016

(C) 2016 The Author(s). Published by S. Karger AG, Base

www.karger.com/kbr

recruitment domain) and caspase-1. This inflammasome is activated by a variety of danger signals such as extracellular ATP, urate crystals, cholesterol crystal and $\beta$-amyloid to form large multi-molecular complexes that activate caspase- 1 and produce bioactive IL-1 $\beta$, IL-18 and other products such as high mobility group box (HMGB1) [1-3]. Nlrp3 inflammasomes have been considered as a cellular machinery responsible for the activation of innate immune response and instigation of sterile inflammation during a variety of chronic degenerative diseases such as atherosclerosis [2,4,5] and Alzheimer's disease [6], as well as in various autoinflammatory diseases including obesity $[7,8]$, diabetes [9, 10], gout [11], silicosis [12], and acetaminophen-induced liver toxicity [13]. In particular, several primary renal diseases and systemic diseases affecting the kidney are associated with Nlrp3 inflammasomes including ureteric obstruction [14], ischemia reperfusion injury [15], glomerulonephritis [16, 17], hyperhomocysteinemia-induced glomerular injury $[8,18,19]$, and crystal nephropathy $[20$, 21]. However, the functional significance of the inflammasome in the kidney remains poorly understood and the precise mechanisms mediating the activation and regulation of Nlrp3 inflammasomes in different renal diseases are not yet defined.

The present study was designed to characterize the Nlrp3 inflammasome in the mouse kidney and to observe where this inflammasome is enriched in different kidney regions and nephron segments. Then, we went on to test whether Nlrp3 inflammasome activation in the renal medulla is involved in the regulation of renal excretory function and renal hemodynamics. In these experiments, we used monosodium urate (MSU) as an Nlrp3 inflammasome activator to stimulate medullary inflammasomes and then observe the effects of activated inflammasomes to alter renal function and hemodynamics. In addition, the inhibitor of caspase-1 activated by Nlrp3 inflammasomes and gene deletion of Nlrp3 and its adaptor ASC gene were used to test whether inhibition or disruption of Nlrp3 inflammasome activation blocks the MSU-induced alterations in renal excretory function and renal regional blood flow, which define the role of this inflammasome activation in the regulation of renal function as a mediating mechanism.

MSU was chosen because uric acid and its crystal formation were recognized as the causative factor in gout $[22,23]$, which is considered as a typical auto-inflammatory disease largely associated with excessive activation of caspase-1. Recent studies have indicated that uric acid is a strong activator of Nlrp3 inflammasomes and its active form, MSU is now used as a standard or positive control in inflammasome studies [11,24]. It is imperative to know whether this MSU-activated inflammasome alters renal medullary function, water and sodium excretion if it is administrated in to the renal medulla.

\section{Material and Methods}

Animals

Eight weeks old male C57BL/6J wild type mice, Nlrp3 knockout (Nlrp3 KO, Mutant Mouse Research and Resource Center) mice, and Asc knockout (Asc K0, Genentech Inc.) mice in the C57BL/6 background (Jackson Laboratories, Bar Harbor, ME) were used in the present study. The mice were allowed free access to standard chow and water ad libitum. All protocols were approved by the Institutional Animal Care and Use Committee of the Virginia Commonwealth University.

\section{Anesthetized mouse studies}

The surgical procedure was modified on the base of previous studies [25-28]. Briefly, Mice were anesthetized with ketamine (30 mg/kg im) plus Inactin $(100 \mathrm{mg} / \mathrm{kg}$ ip) and body temperature was maintained on a thermostatically controlled warming table at $37.5^{\circ} \mathrm{C}$. Supplemental doses of Inactin anesthesia was administered as required. A tracheotomy was performed to facilitate breathing air enriched $95 \% \mathrm{O}_{2}$ and $5 \% \mathrm{CO}_{2}$. After tracheostomy, the right jugular vein was catheterized to deliver maintenance fluids 


\section{Kidney Blood Pressure Research}

infusion with $2 \%$ bovine serum albumin in saline $(10 \mathrm{ml} / \mathrm{kg} / \mathrm{h})$ and the left carotid artery was cannulated to measure arterial blood pressure (MAP). The left kidney was exposed and placed its dorsal side up in a kidney cup via a midline incision. For renal medullary infusion, a catheter (tapered tip, 1.5-2 mm) was gently implanted into the medulla vertically from the dorsal surface and anchored into place on the kidney surface with Vetbond Tissue Adhesive (3M). The catheter was infused with PBS containing (in mM) 205

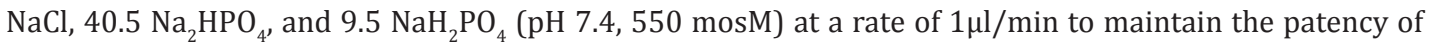
interstitial infusion. For the renal hemodynamics analysis, a dual-channel laser-Doppler flowmeter (model BLF 21D; Transonic Systems, Inc.) with optical fiber needle probes (Transonic) were on the surface of the renal cortex to measure cortical blood flow ( $\mathrm{CBF}$ ) and implanted fiber (500 $\mu \mathrm{m}$ diameter, $2 \mathrm{~mm}$ depth) into the renal medulla to measure medullary blood flow (MBF). At the end of each experiment, the kidney was dissected and checked to confirm the fiber probe location and verify whether tissue damage occurred surrounding the fiber tip. For excretory function analysis, the bladder was catheterized with PE-50 tubing for urine collections.

\section{Experimental protocols}

After a 1.5-h equilibration period and two 20-min control sample collections in mice infused with vehicles (10-min clearance period and 20-min sample collection), different reagents were administrated into the renal medulla for $30 \mathrm{~min}$ via renal interstitial catheter. They include Group 1: infusion of MSU (Sigma Chemical Co., St. Louis, MO) at $0.1,0.3$ and $0.6 \mathrm{mg} \cdot \mathrm{kg}^{-1} \cdot \mathrm{min}^{-1}$; Group 2: infusion of MSU at $0.1,0.3$ and $0.6 \mathrm{mg} \cdot \mathrm{kg}^{-1} \cdot \mathrm{min}^{-1}$ plus caspase-1 inhibitor Ac-YVAD-CMK. Group 3: infusion of MSU at 0.1, 0.3 and 0.6 $\mathrm{mg} \cdot \mathrm{kg}^{-1} \cdot \mathrm{min}^{-1}$ in WT and Nlrp3 knockout mice; Group 4: infusion of MSU at 0.1, 0.3 and $0.6 \mathrm{mg} \cdot \mathrm{kg}^{-1} \cdot \mathrm{min}^{-1}$ in WT and ASC knockout mice. This surgical preparation and protocol procedure have been widely used in the studies of renal physiology and our previous studies [28-30]. In our preliminary experiments, we found that the effects of renal medullary interstitial infusion of any of these compounds can reach a plateau at 1520 minutes as an infused compound is accumulated in the medulla due to its concentration action. For this reason, we chose a 30-min interval for infusion of each dose as a clearance period. Infusion of vehicle alone does not produce time course change in renal function over the period of experiment time

\section{Microdissection of nephron segments in the mouse kidney}

Microdissection method was modified as we described previously [31, 32]. Briefly, in anesthetized mouse, the left kidney was flushed with $20 \mathrm{ml}$ ice-cold dissection solution containing (in mM) $135 \mathrm{NaCl}, 3 \mathrm{KCl}$, $1.5 \mathrm{CaCl} 2,1 \mathrm{MgSO} 4,2 \mathrm{KH} 2 \mathrm{PO} 4,5.5$ glucose, 5 L-alanine, and 5 HEPES (pH 7.4) and following the perfusion with $10 \mathrm{ml}$ digestion solution including $1 \mathrm{mg} / \mathrm{ml}$ collagenase $(243 \mathrm{U} / \mathrm{mg}$, Worthington Biochemical, Lakewood, $\mathrm{NJ}$ ) and $1 \mathrm{mg} / \mathrm{ml}$ bovine albumin within dissection solution. After perfusion, the kidney was removed and cut into 1- to 2-mm-thick sections containing the entire corticomedullary axis and incubated at $37^{\circ} \mathrm{C}$ for 30 min with gentle shaking by bubbling with 95\% $\mathrm{O}_{2}-5 \% \mathrm{CO}_{2}$. The sections were then rinsed twice with collagenase-free sorting solution and transferred into petri dishes filled with ice-cold dissection solution containing $0.1 \mathrm{mg} / \mathrm{ml}$ trypsin inhibitor and $20 \mu \mathrm{g} / \mathrm{ml}$ aprotinin. Microdissection was performed under a Leica MZ8 stereomicroscope with darkfield illumination with a cooling system to maintain the microscope stage at $4^{\circ} \mathrm{C}$ during dissection. The nephron segments including glomeruli, proximal tubule (PT), cortical thick ascending limb of Henle's loop (cTAL), medullary thick ascending limb of Henle's loop (mTAL), cortical collecting duct (CCD), and medullary collecting duct (MCD) were dissected. The time period for dissection was limited to 1 hour. 25 glomeruli and $20 \mathrm{~mm}$ tubules (PT, cTAL, mTAL, CCD and MCD) were collected for RT-PCR assay. We collected cortex and medullary tissue separately for microdissection and when TALs are form cortex, we named as CTAL; if TALs are from medullary tissue, we gave a name of mTAL.

\section{Reverse transcription polymerase chain reaction (RT-PCR)}

Total RNA from isolated nephron segments was extracted using TRIzol reagent (Invitrogen, Carlsbad, CA) according to the protocol as described by the manufacturer [18]. RNA samples were quantified by measurement of optic absorbance at $260 \mathrm{~nm}$ and $280 \mathrm{~nm}$ in a spectrophotometer. Aliquots of total RNA (1 $\mu \mathrm{g})$ from each sample were reverse-transcribed into cDNA according to the instructions of the first strand cDNA synthesis kit manufacturer (Bio-Rad, Hercules, CA). Equal amounts of the reverse transcriptional products were subjected to PCR amplification using SYBR Green as the fluorescence indicator on a Bio-Rad iCycler system 


\section{Kidney Blood Pressure Research}

(Bio-Rad, Hercules, CA). The primers used in this study were synthesized by Operon (Huntsville, AL) and the sequences were: Nlrp3 sense 5'-TACGGCCGTCTACGTCTTCT-3', antisense 5'-CGCAGATCACACTCCTCAAA-3'; for Asc sense 5'-ACAGAAGTGGACGGAGTGCT-3', antisense 5'-CTCCAGGTCCATCACCAAGT-3'; for caspase-1 sense 5'-CACAGCTCTGGAGATGGTGA-3', antisense 5'-TCTTTCAAGCTTGGGCACTT-3'; and for $\beta$-actin sense 5'-TCGCTGCGCTGGTCGTC-3', antisense 5'-GGCCTCGTCACCCACATAGGA-3'.

\section{Western blot analysis}

Western blot analysis was performed as we described previously [18]. In brief, homogenates from kidney tissues were prepared using sucrose buffer containing protease inhibitors. After boiling for $5 \mathrm{~min}$ at $95^{\circ} \mathrm{C}$ in a $5 \times$ loading buffer, $20 \mu \mathrm{g}$ of total proteins were subjected to SDS-PAGE, transferred onto a PVDF membrane and blocked by solution with dry milk. Then, the membrane was probed with primary antibodies of anti-caspase-1 (1:200, Santa Cruz Biotechnology), or anti- $\beta$-actin (1:5000, Santa Cruz Biotechnology) overnight at $4{ }^{\circ} \mathrm{C}$ followed by incubation with horseradish peroxidase-labeled IgG (1:5000). The immunoreactive bands were detected by chemiluminescence methods and visualized on Kodak Omat $\mathrm{X}$-ray films. Densitometric analysis of the images obtained from X-ray films was performed using the Image J software (NIH, Bethesda, MD, USA).

\section{Caspase- 1 activity and IL-1 $\beta$ production in mouse tissue}

Caspase-1 activity was measured by a commercially available colorimetric assay kit (Biovision, Mountain View, CA) as we described previously [19]. IL-1 $\beta$ production was measured by a commercially available ELISA kit (R\&D System, Minneapolis, MN), according to the manufacturer's instructions. The data was expressed as the fold changes compared with control.

\section{Immunohistochemistry}

Kidneys were embedded with paraffin and $5 \mu \mathrm{m}$ sections were cut from the embedded blocks. After heat-induced antigen retrieval, 20 min wash with $3 \% \mathrm{H}_{2} \mathrm{O}_{2}$ and 30 min blocking with serum, the slides were incubated with primary antibodies diluted in phosphate-buffered saline (PBS) with $4 \%$ serum. Anti-Nlrp3 (1:100), anti-Asc (1:200) and anti-caspase-1 (1:100) antibodies was used in this study. After incubation with primary antibody overnight, the sections were washed in PBS and incubated with biotinylated IgG (1:200) for 1 hour and then with streptavidin-HRP for $30 \mathrm{~min}$ at room temperature. $50 \mu \mathrm{l}$ of DAB (3,3'-diaminobenzidine) was added to each kidney section and stained for $1 \mathrm{~min}$. After washing, the slides were counterstained with hematoxylin for $5 \mathrm{~min}$. The slides were then mounted and observed under a microscope in which photos were taken. All antibodies were purchased from Abcam (Cambridge, MA).

\section{Confocal microscopic analysis}

Immunofluorescent staining was used to determine colocalization of the inflammasome proteins with different tubule markers in mouse kidney. Frozen kidney tissue slides were fixed in acetone and then immuno stained with either anti-Nlrp3 (1:100, Novus Biologicals), anti-Asc (1:200, Enzo Lifesciences), or anti-caspase-1 (1:100, Santa Cruz Biotechnology) and then with Alexa-555-labeled secondary antibodies (Invitrogen, Grand Island, NY). After washing, we double stained tissues in the slides with FITC-labeled Lotus tetragonolobus agglutinin (LTA, 1:200, Vector Laboratories, Burlingame, CA), anti-Tamm-Horsfall antigen (anti-THP, 1:200, Chemicon, Billerica, MA) with Alexa-488-labeled secondary antibody and FITClabeled Dolichos Biflorus Agglutinin (DBA, 1:200, Vector Laboratories, Burlingame, CA) for identification of tubular segments. These slides were then mounted with a DAPI-containing mounting solution, and then observed with a confocal laser scanning microscope (Fluoview FV1000, Olympus, Japan).

\section{Statistics}

Data are presented as means \pm SE. Significant differences between and within multiple groups were examined using ANOVA for repeated measures, followed by Duncan's multiple-range test. Student's t-test was used to examine the significance of differences in measured parameters between two groups of experiments. $\mathrm{P}<0.05$ was considered statistically significant. 


\section{Kidney Blood Pressure Research}

Results

Identification of Nlrp3 inflammasomes in the mouse kidney

First we characterized the Nlrp3 inflammasomes in the mouse kidneys. In dissected mouse renal cortex, outer medulla (OM) and inner medulla (IM), Western blot analysis showed that inflammasomes components Nlrp3, Asc and caspase-1 were detectable as shown in Figure 1A. The activation of Nlrp3 inflammasomes was also found by measurement of caspase- 1 activity and IL-1 $\beta$ production in all 3 different renal regions (Figure $1 \mathrm{~B}$ ), and it was significantly higher in the OM compared to the renal cortex and inner medulla, suggesting that the outer medulla may be the kidney region with Nlrp3 inflammasome formation even under normal condition. Immunohistochemistry was performed to further define the location of three proteins in the kidney. As shown in Figure 1C, Nlrp3, Asc and caspase-1 were predominantly expressed in tubular and vascular walls, particularly in the renal cortex and outer medulla. It is clear that the Nlrp3 inflammasome molecules are ubiquitously expressed in all kidney regions, in both renal vessels and tubules.

\section{Distribution of Nlrp3 inflammasomes in} different nephron segments

In micro dissected glomeruli and different tubules (Figure 2A), RT-PCR analysis revealed that Asc mRNA was detected in all nephron segments including glomeruli. In cortical and medullary thick ascending limb (cTAL and mTAL), all three Nlrp3 inflammasome molecules were found more abundant compared to other nephron segments (Figure 2B). In addition, the colocalization assay by confocal microscopy showed that there were partial colocalizations between Nlrp3 and connecting tubule marker, DBA in the outer medulla; Asc and proximal tubule marker, LTL and DBA in the cortex; as well as between caspase- 1 and LTL in the cortex. Only in the outer medulla area, the co-localization of three Nlrp3 inflammasome proteins with thick ascending limb marker, THP was detected (Figure 2C). Such co-localization of Nlrp3 molecules further confirmed that $\mathrm{OM}$ may be the renal

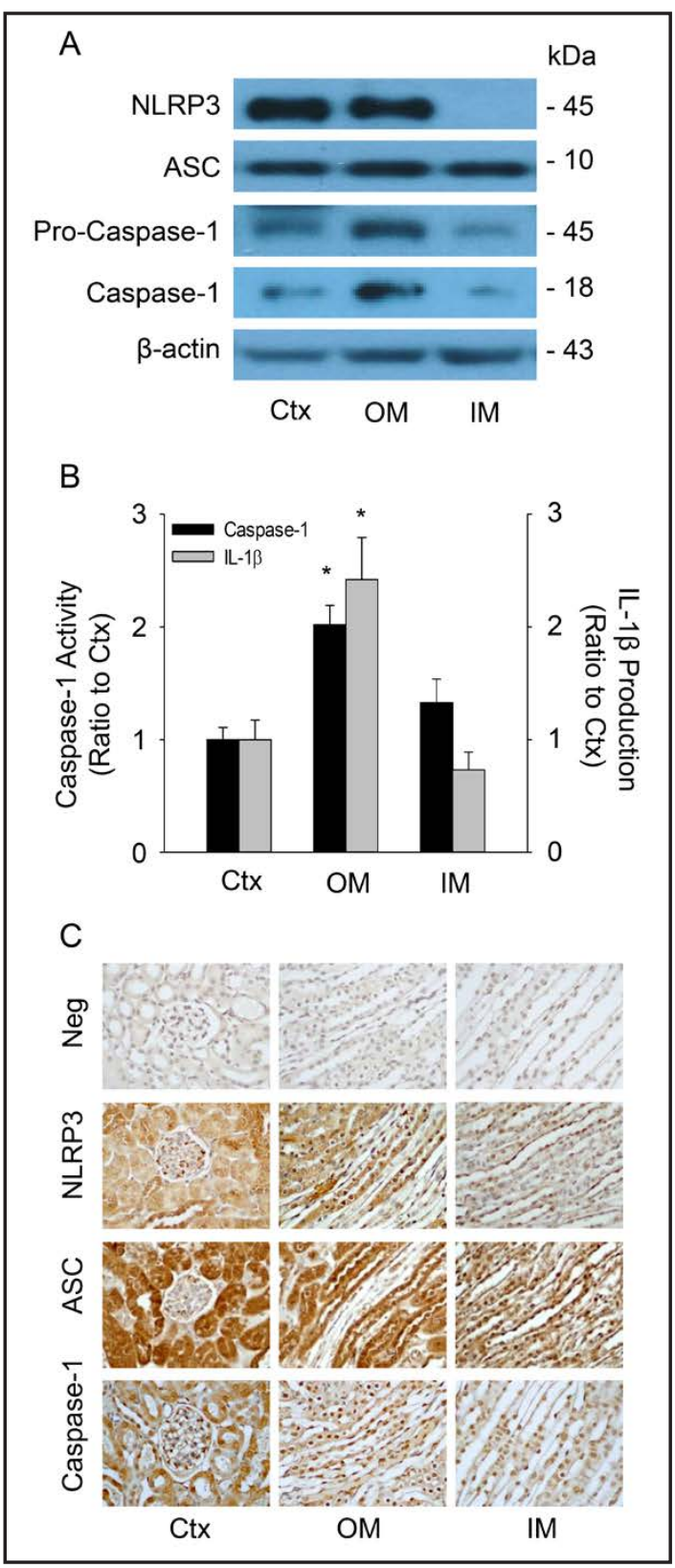

Fig. 1. Characterizations of Nlrp3 inflammasome components in mouse kidney. (A) Western blot analysis showing the protein expression of Nlrp3, Asc, pro-caspase- 1 and cleaved caspase- 1 in the different areas of the mouse kidney. Ctx: cortex, OM: outer medulla, IM: inner medulla. $n=4$ mice per group. (B) Values are arithmetic means \pm SEM ( $n=4$ each group) of caspase- 1 activity and IL- $1 \beta$ production in different areas of the mouse kidney. ${ }^{*} \mathrm{P}<0.05$ vs. Control (Ctx). (C) Immunohistochemical analysis of inflammasome molecules in the mouse kidney. Neg: negative control, Ctx: Control. 


\section{Kidney \\ Blood Pressure \\ Research}

Kidney Blood Press Res 2016;41:208-221

DOI: $10.1159 / 000443424$

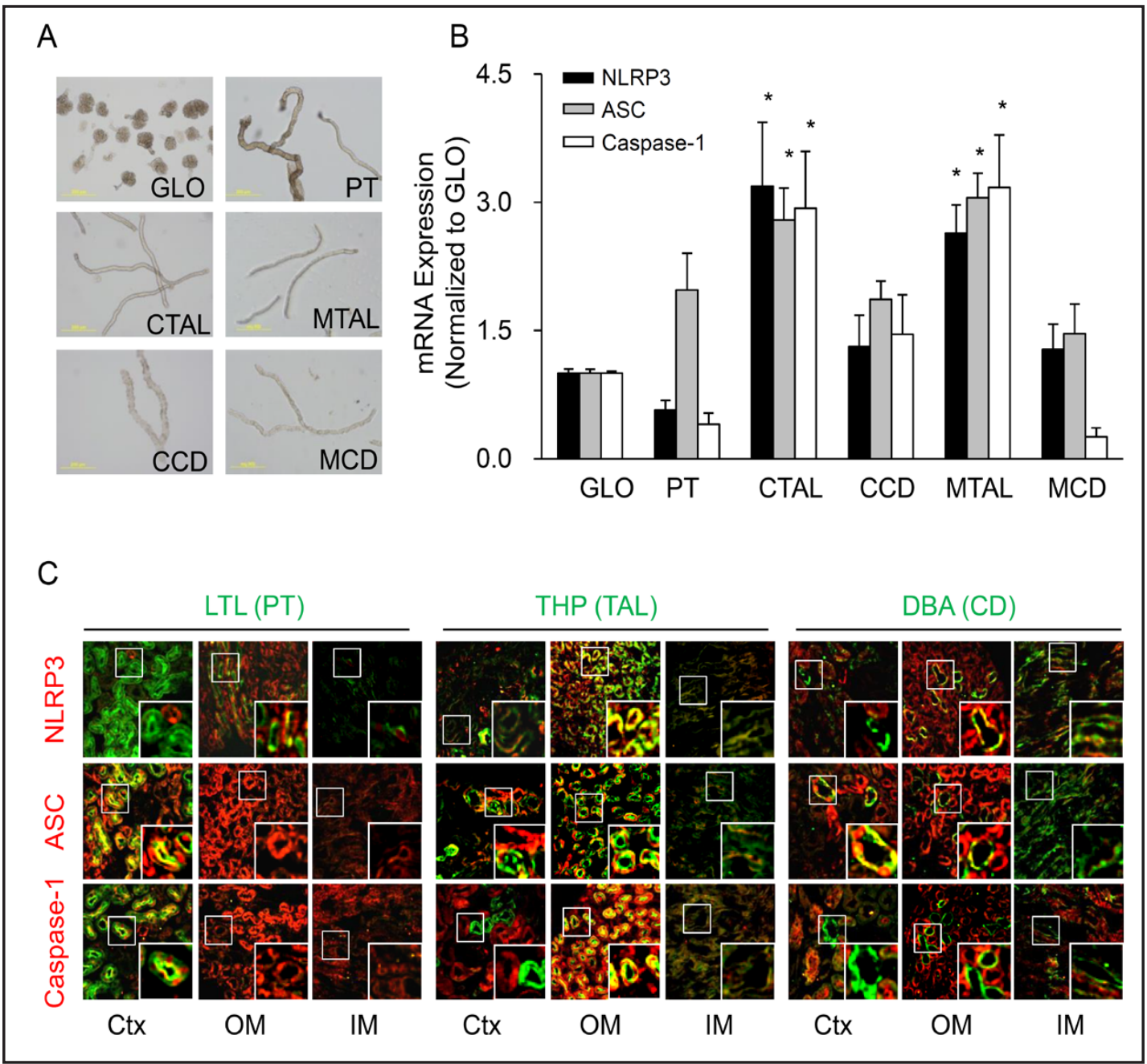

Fig. 2. Distribution of Nlrp3 inflammasome components in different nephron segments. (A) Representative images of isolated nephron fragments: glomeruli (GLO), proximal tubule (PT), cortical thick ascending limb (CTAL), medullary thick ascending limb (MTAL), cortical connecting tubule (CCD) and medullary connecting tubule (MCD). (B) Quantitative RT-PCR analysis showing the distribution of Nlrp3, Asc and caspase-1 mRNA levels in different nephron segments. Values are arithmetic means \pm SEM ( $\mathrm{n}=6$ mice per group), ${ }^{*} \mathrm{P}<0.05$ vs. glomeruli. (C) Fluorescent confocal microscopic images showing co-localization of inflammasome components (red): Nlrp3, Asc or caspase-1 with different renal tubular markers (green): Proximal tubule (PT) marker: Lotus tetragonolobus Agglutinin (LTL); Thick ascending limb (TAL) marker: Tamm-Horsfall protein antibody (THP); and Connecting tubule (CD) marker: Dolichos biflorus agglutinin (DBA) in mouse.

area with the highest potential to activate Nlrp3 inflammasomes through their high activity in MTALs.

Effects of intrarenal (i.r.) infusion of Nlrp3 inflammasome stimulator MSU into the renal medulla on renal hemodynamics and excretory functions

The influence of MSU on mean arterial blood pressure (MAP), cortical blood flow (CBF) and medullary blood flow (MBF) was illustrated in Figure 3. In anesthetized mice, basal line of mean arterial blood pressure averaged $93.17 \pm 5.92 \mathrm{mmHg}$ before MSU administration. After different doses of i.r. MSU, there were no significant changes in mean arterial blood pressure. However, MSU produced a concentration-dependent decrease in medullary blood flow with a maximal reduction of around $10 \%$, but it had no effect on cortical blood flow. In 


\section{Kidney Blood Pressure Research}

another group of mice with pre-infusion of caspase-1 inhibitor, Ac-YVAD-CMK (1mg/ $\mathrm{Kg} / \mathrm{min}$ ) for 30 mins, MSU failed to reduce medullary blood flow (Figure 3). The effects of MSU on renal water, sodium and potassium excretion were summarized in Table 1. MSU i.r significantly decreased urine volume by $52.6 \%$ and sodium excretion by $66.9 \%$, but had no effect on potassium excretion. In mice with preadministration of YVAD, MSU-induced effects on renal function were substantially attenuated.

Effects of i.r. MSU on Nlrp3 inflammasome activation in the renal medulla

To test how MSU decreases medullary blood flow, urine volume and urinary sodium excretion, several biochemical analyses were performed to evaluate whether Nlrp3 inflammasomes are activated in the renal medullary tissue after MSU infusion. The results obtained from Western blot analysis showed that the cleaved or active caspase-1 (18 kD) levels were increased in MSU i.r medullary tissue (Figure 4A). As summarized in the bar graph, the cleavage of pro-caspase-1 into bioactive caspase- 1 , which indicates Nlrp3 inflammasome activation, was

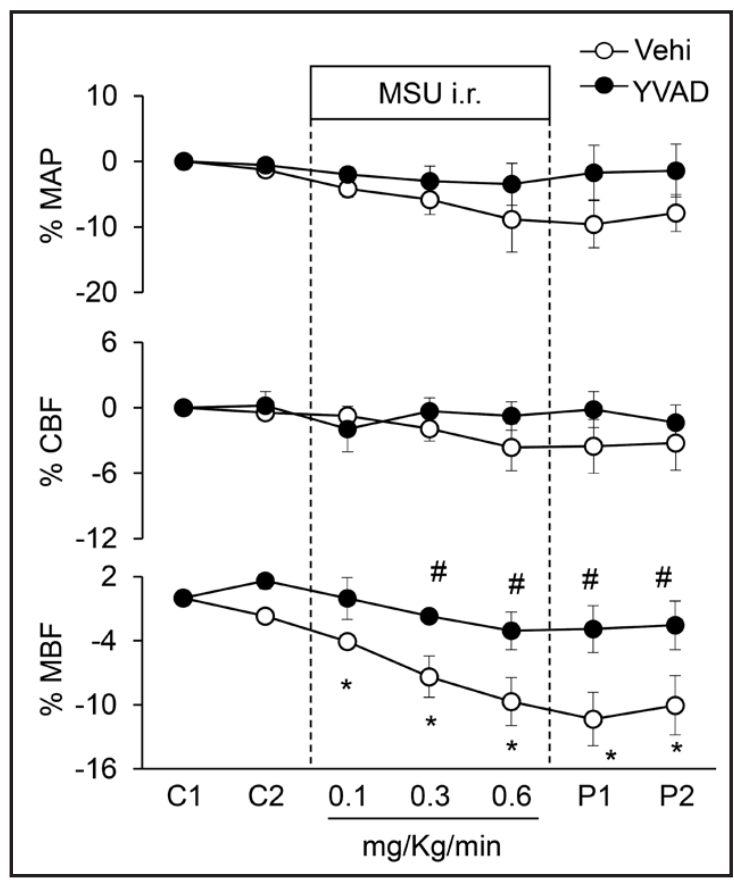

Fig. 3. Effects of renal medullary interstitial (i.r.) infusion of inflammasome stimulator, monosodium urate (MSU) on renal blood flows in anesthetized mice. YVAD: caspase-1 inhibitor Ac-YVAD-CMK (1mg/Kg/ min, 30 mins). MAP: mean arterial blood pressure; CBF: renal cortical blood flow; MBF: renal medullary blood flow. C: control period, P: post period. Values are arithmetic means \pm SEM ( $n=6$ mice per group), * $\mathrm{P}<0.05$ vs. control periods; \# $\mathrm{P}<0.05$ vs. vehicle group. significantly increased by i.r. MSU. This MSU-induced increase in active capase-1 level in the renal medulla was remarkably inhibited by the co-infusion of YVAD with MSU. By colorimetric assay, it was found that MSU infusion significantly augmented caspase-1 activity in renal medullary tissue, which was notably attenuated by YVAD (black bars in Figure 4B). Moreover, MSU also significantly increased IL-1 $\beta$ concentration in renal medullary tissues and were blocked by the YVAD pre-treatment (grey bars in Figure 4B). Collectively, these results provide evidence that renal medullary

Table1. Effects of MSU i.r. infusion on renal function in mice receiving vehicle and caspase-1 inhibitor

\begin{tabular}{ccccccc}
\hline & & Control & 0.1 & 0.3 & 0.6 & Post \\
\hline $\begin{array}{c}\mathrm{U} \bullet \mathrm{V} \\
(\mu \mathrm{min} / \mathrm{gkw})\end{array}$ & Vehl & $14.60 \pm 0.47$ & $9.82 \pm 1.56$ & $6.58 \pm 2.00 *$ & $4.65 \pm 1.79 *$ & $5.28 \pm 2.30 *$ \\
& YVAD & $15.80 \pm 1.34$ & $14.91 \pm 1.75$ & $14.27 \pm 1.66$ & $12.10 \pm 1.50$ & $12.72 \pm 1.40$ \\
$\mathrm{U}_{\mathrm{Na}} \cdot \mathrm{V}$ & Vehl & $3.87 \pm 0.31$ & $2.59 \pm 0.34$ & $1.64 \pm 0.47 *$ & $1.17 \pm 0.41 *$ & $1.39 \pm 0.39 *$ \\
$(\mu \mathrm{mol} / \mathrm{min} / \mathrm{gkw})$ & YVAD & $4.01 \pm 0.39$ & $3.65 \pm 0.26$ & $3.55 \pm 0.28$ & $2.97 \pm 0.39$ & $3.40 \pm 0.46$ \\
$\mathrm{U}_{\mathrm{K}} \bullet \mathrm{V}$ & Vehl & $1.61 \pm 0.32$ & $1.42 \pm 0.19$ & $1.41 \pm 0.20$ & $1.39 \pm 0.21$ & $1.52 \pm 0.19$ \\
$(\mu \mathrm{mol} / \mathrm{min} / \mathrm{gkw})$ & YVAD & $1.50 \pm 0.11$ & $1.53 \pm 0.11$ & $1.49 \pm 0.09$ & $1.45 \pm 0.08$ & $1.48 \pm 0.11$ \\
\hline
\end{tabular}

$\mathrm{U} \bullet \mathrm{V}$ : urine volume, $\mathrm{U}_{\mathrm{Na}} \bullet \mathrm{V}$; urinary sodium excretion, $\mathrm{UK}_{\mathrm{K}} \bullet \mathrm{V}$; urinary potassium excretion. Values are arithmetic means \pm SEM $\left(\mathrm{n}=6\right.$ mice per group), ${ }^{*} \mathrm{P}<0.05$ vs. control periods. 


\section{Kidney Blood Pressure Research}

Nlrp3 inflammasome activation by MSU may be the cause of decrease in MBF and water/sodium excretion.

Effects of Nlrp3 gene deletion on i.r. $M S U$-induced changes in renal hemodynamics and excretory function

We next tested the role of activated Nlrp3 inflammasome in the regulation of medullary blood flow, urine volume and urinary sodium excretion by using Nlrp3 gene knockout (KO) mice. As shown in Figure 5 and Table 2, in wild-type mice i.r. MSU significantly decreased medullary blood flow, urine volume and urinary sodium excretion by $10.7 \%, 51.2 \%$, and $47.4 \%$, respectively. However, such decreases in renal hemodynamics and renal function were abolished in Nlrp3 KO mice. MSU had no effects on mean arterial blood pressure and cortical blood flow in both WT and Nlrp3 KO mice.

Nlrp3 gene deletion blocked renal medullary Nlrp3 inflammasome activation induced by $M S U$

As illustrated in Figure 6, biochemical analyses demonstrated that the cleavage of pro-caspase- 1 into active caspase-1 induced by MSU was blocked in renal medullary tissue from Nlrp3 KO mice compared with their WT controls. Correspondingly, MSU-induced enhancement of renal medullary caspase- 1 activity and IL-1 $\beta$ production was demonstrated in WT mice, but was undetectable in Nlrp3 KO mice.

ASC gene deletion abolished i.r. MSUinduced decrease in medullary blood flow and renal excretory function

We also used Asc gene knockout mice to examine whether activated Nlrp3 inflammasome indeed participate in the

Fig. 5. Effects of Nlrp3 gene deletion on MSU-induced alterations of renal blood flows in anesthetized mice. WT: C57BL/6J mice; Nlrp3 KO: Nlrp3 gene knockout mice. MAP: mean arterial blood pressure; CBF: renal cortical blood flow; MBF: renal medullary blood flow. C: control period, P: post period. Values are arithmetic means \pm SEM ( $\mathrm{n}=6$ mice per group), ${ }^{*} \mathrm{P}<0.05$ vs. control periods; \# $\mathrm{P}<0.05$ vs. vehicle group.

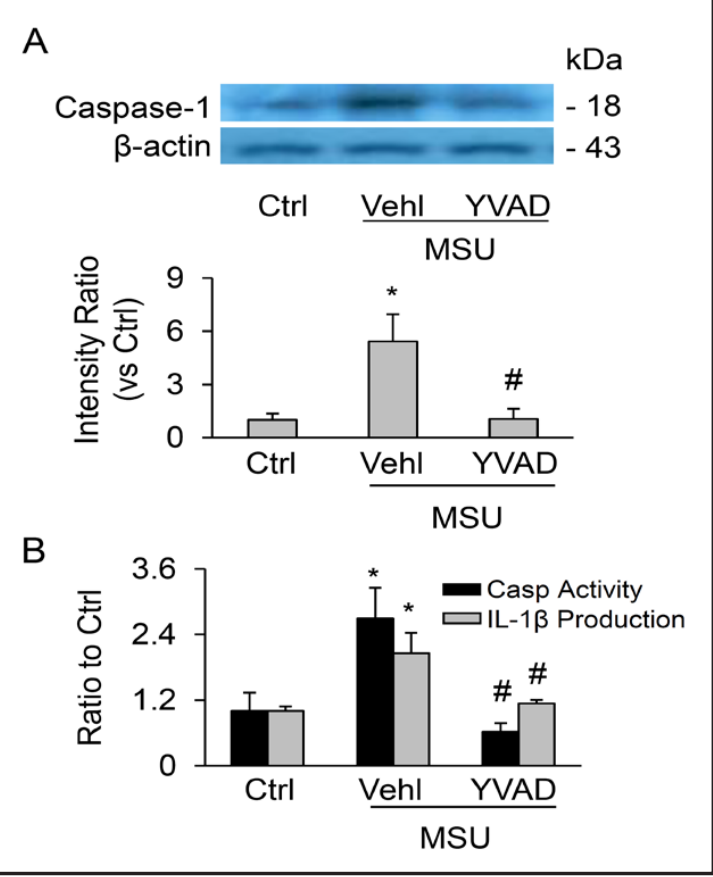

Fig. 4. Activation of renal medullary inflammasomes by i.r. MSU. (A) Western blot analysis showing MSU-induced increase in cleaved caspase- 1 level in the medulla in the absence and presence of Ac-YVAD-CMK. (B) MSU-induced increase in caspase- 1 activity and IL-1 $\beta$ production in the renal medulla. $n=6$ mice per group. Ctrl: control, Vehl: vehicle, YVAD: Ac-YVAD-CMK. Values are arithmetic means \pm SEM ( $\mathrm{n}=6$ mice per group), * $\mathrm{P}<0.05$ vs. control periods; \# $\mathrm{P}<0.05$ vs. vehicle group.

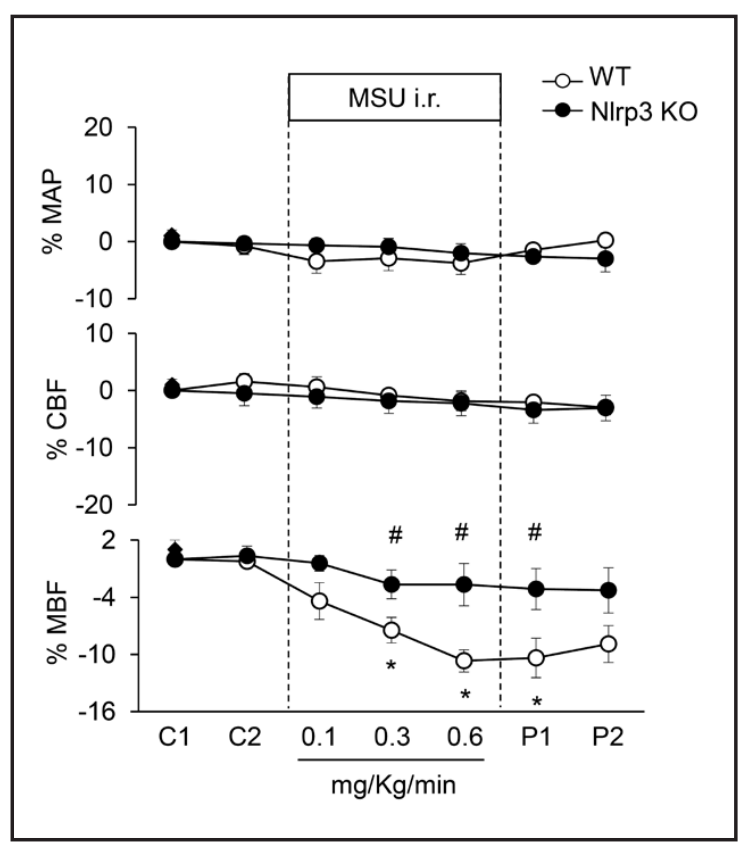




\section{Kidney Blood Pressure Research}

Table2. Effects of MSU i.r. infusion on renal function in WT and Nlrp3 KO mice

\begin{tabular}{ccccccc}
\hline & & Control & 0.1 & 0.3 & 0.6 & Post \\
\hline $\begin{array}{c}\mathrm{U} \bullet \mathrm{V} \\
(\mu \mathrm{l} / \mathrm{min} / \mathrm{gkw})\end{array}$ & WT & $15.62 \pm 1.93$ & $13.30 \pm 2.10$ & $7.75 \pm 1.22 *$ & $7.51 \pm 1.61 *$ & $9.57 \pm 2.24$ \\
& Nlrp3KO & $17.98 \pm 2.71$ & $16.76 \pm 2.99$ & $16.00 \pm 3.18$ & $16.02 \pm 3.27$ & $16.45 \pm 2.91$ \\
$\mathrm{U}_{\mathrm{Na}} \bullet \mathrm{V}$ & $\mathrm{WT}$ & $5.23 \pm 0.52$ & $4.60 \pm 0.55$ & $2.75 \pm 0.25 *$ & $3.08 \pm 0.53 *$ & $3.83 \pm 0.55$ \\
$(\mu \mathrm{mol} / \mathrm{min} / \mathrm{gkw})$ & Nlrp3KO & $5.08 \pm 0.26$ & $4.87 \pm 0.28$ & $4.56 \pm 0.17$ & $4.52 \pm 0.22$ & $4.71 \pm 0.28$ \\
$\mathrm{U}_{\mathrm{K}} \bullet \mathrm{V}$ & $\mathrm{WT}$ & $1.73 \pm 0.23$ & $1.69 \pm 0.22$ & $1.65 \pm 0.12$ & $1.65 \pm 0.20$ & $1.73 \pm 0.23$ \\
$(\mu \mathrm{mol} / \mathrm{min} / \mathrm{gkw})$ & Nlrp3KO & $1.67 \pm 0.28$ & $1.65 \pm 0.22$ & $1.56 \pm 0.20$ & $1.66 \pm 0.23$ & $1.61 \pm 0.20$ \\
\hline
\end{tabular}

$\mathrm{U} \bullet \mathrm{V}$ : urine volume, $\mathrm{U}_{\mathrm{Na}} \bullet \mathrm{V}$; urinary sodium excretion, $\mathrm{U}_{\mathrm{K}} \bullet \mathrm{V}$; urinary potassium excretion. Values are arithmetic means \pm SEM ( $\mathrm{n}=6$ mice per group), ${ }^{*} \mathrm{P}<0.05 \mathrm{vs}$. control periods.

regulation of medullary blood flow, urine volume and urinary sodium excretion. As shown in Figure 7 and Table 3, wild-type mice i.r. MSU did not decrease medullary blood flow, urine volume and urinary sodium excretion in Asc knockout mice, which was similar to that observed in Nlrp3 knockout mice. Similarly, MSU i.r had no effects on mean arterial blood pressure and cortical blood flow in both WT and Asc knockout mice.

No activation of renal medullary inflammasomes by i.r. MSU in ASC knockout mice By biochemical analyses, the cleavage of pro-caspase-1 into active caspase-1 induced by MSU in renal medullary tissue was stimulated by i.r. MSU only in WT mice, but not in Asc knockout mice, suggesting no activation of caspase- 1 in these Asc knockout mice. The lack of Nlrp3 activation in Asc knockout mice was also confirmed by measurements of renal medullary caspase-1 activity and IL-1 $\beta$ production (Figure 8 ).

\section{Discussion}

The present study demonstrated that, in the renal medulla, Nlrp3 and Asc were highly expressed and endogenous pro-capase-1 and cleaved caspase- 1 had a remarkably high level as shown by Western blot analysis. By RT-PCR analysis of these inflammasome molecules in isolated nephron segments in combination with confocal microscopy, we found that the Nlrp3 inflammasome proteins were abundant in thick ascending

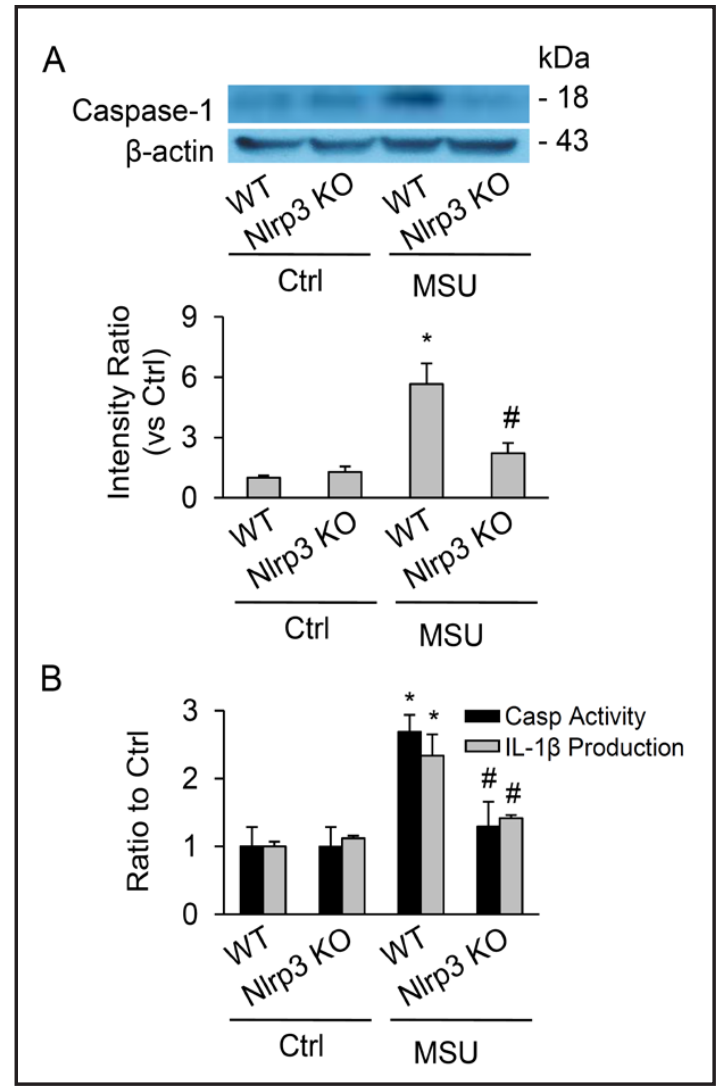

Fig. 6. Failure of i.r. MSU to activate renal medullary inflammasomes. (A) Western blot analysis showing MSU-induced increase in cleaved caspase- 1 levels in WT mice, but not in Nlrp3 knockout mice. (B) Effect of Nlrp3 gene deletion on caspase-1 activity and IL$1 \beta$ production induced by MSU in the renal medulla. Values are arithmetic means \pm SEM $(n=6$ mice per group), ${ }^{*} \mathrm{P}<0.05$ vs. control periods; $\# \mathrm{P}<0.05$ vs WT mice with i. r. MSU. WT: C57BL/6J mice; Nlrp3 KO: Nlrp3 gene knockout mice. 


\section{Kidney \\ Blood Pressure Research}

Table 3. Effect of MSU i.r. infusion on renal function in WT and Asc KO mice

\begin{tabular}{ccccccc}
\hline & & Control & 0.1 & 0.3 & 0.6 & Post \\
\hline $\begin{array}{c}\mathrm{U} \bullet \mathrm{V} \\
(\mu \mathrm{l} / \mathrm{min} / \mathrm{gkw})\end{array}$ & WT & $15.72 \pm 1.96$ & $12.47 \pm 2.17$ & $7.28 \pm 1.26^{*}$ & $6.36 \pm 1.27 *$ & $8.39 \pm 2.13$ \\
& ASC KO & $15.91 \pm 1.02$ & $15.69 \pm 1.10$ & $14.60 \pm 1.10$ & $14.27 \pm 1.09$ & $15.21 \pm 1.34$ \\
$\mathrm{U}_{\mathrm{Na}} \bullet \mathrm{V}$ & WT & $4.21 \pm 0.21$ & $3.37 \pm 0.28$ & $2.21 \pm 0.18 *$ & $1.95 \pm 0.24 *$ & $2.51 \pm 0.29$ \\
$(\mu \mathrm{mol} / \mathrm{min} / \mathrm{gkw})$ & ASC KO & $5.02 \pm 0.27$ & $5.03 \pm 0.29$ & $4.76 \pm 0.34$ & $4.65 \pm 0.36$ & $4.88 \pm 0.34$ \\
$\begin{array}{c}\mathrm{U}_{\mathrm{K}} \bullet \mathrm{V} \\
(\mu \mathrm{mol} / \mathrm{min} / \mathrm{gkw})\end{array}$ & WT & $1.77 \pm 0.21$ & $1.77 \pm 0.21$ & $1.68 \pm 0.11$ & $1.71 \pm 0.19$ & $1.79 \pm 0.21$ \\
& ASC KO & $1.24 \pm 0.15$ & $1.22 \pm 0.17$ & $1.14 \pm 0.14$ & $1.13 \pm 0.12$ & $1.21 \pm 0.16$
\end{tabular}

$\mathrm{U} \bullet \mathrm{V}$ : urine volume, $\mathrm{U}_{\mathrm{Na}} \bullet \mathrm{V}$; urinary sodium excretion, $\mathrm{U}_{\mathrm{K}} \bullet \mathrm{V}$; urinary potassium excretion. Values are arithmetic means \pm SEM $(\mathrm{n}=6$ mice per group), $* \mathrm{P}<0.05$ vs. control periods.

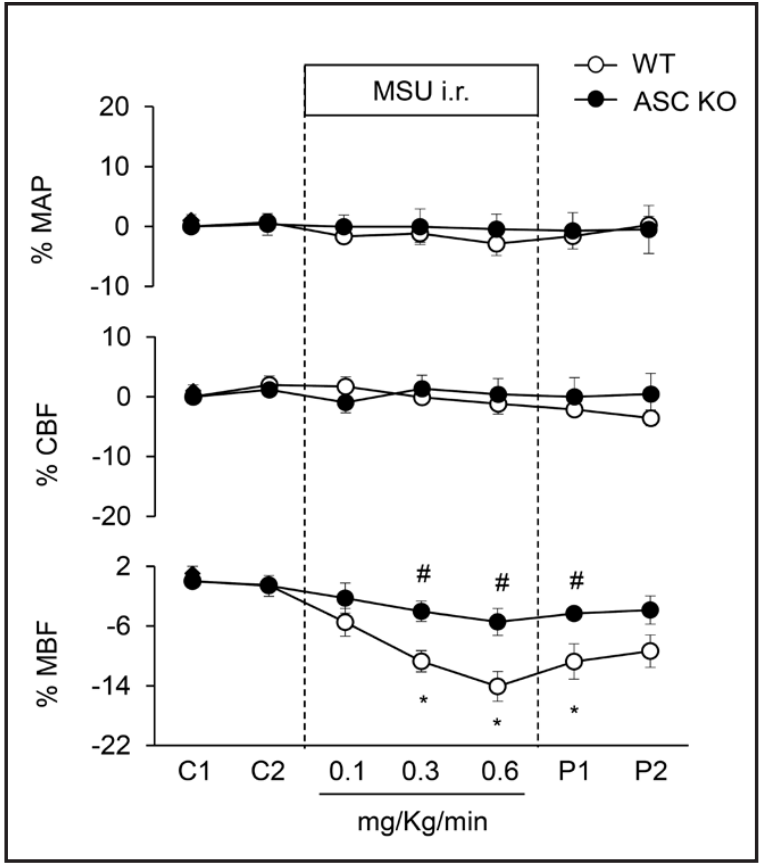

Fig. 7. Effects of Asc gene deletion on MSU-induced alterations of renal blood flows in anesthetized mice. WT: C57BL/6J mice; Asc KO: Asc gene knockout mice. MAP: mean arterial blood pressure; CBF: renal cortical blood flow; MBF: renal medullary blood flow. C: control period, P: post period. Values are arithmetic means \pm SEM $(n=6$ mice per group), ${ }^{*} \mathrm{P}<0.05$ vs. control periods; \# $\mathrm{P}<0.05$ vs. vehicle group.

limb including cTAL and mTAL. These data are consistent with some reports indicating that Nlrp3 and Asc are mainly expressed in murine and human renal tubular epithelium [33]. Our results from biochemical analysis revealed that the renal medulla is a kidney region with the highest caspase- 1 activity and IL-1 $\beta$

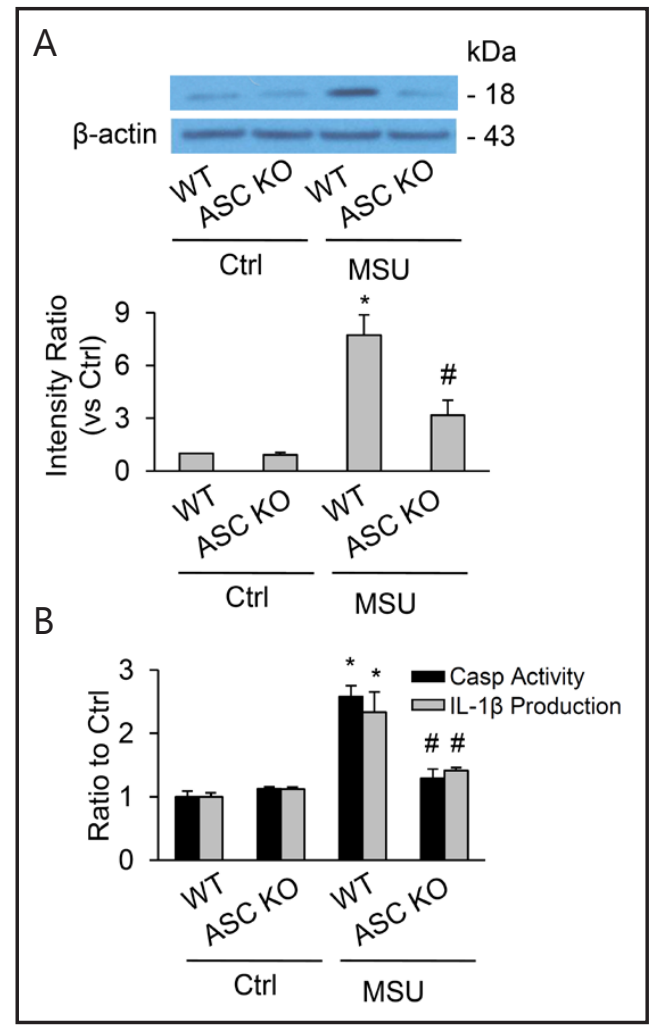

Fig. 8. No activation of renal medullary inflammasomes by i.r MSU in Asc KO mice. (A) Western blot analysis showing MSU-induced increase in cleaved caspase-1 levels in WT mice, but not in ASC KO mice. (B) Effect of ASC gene deletion on caspase- 1 activity and IL-1 $\beta$ production induced by MSU in the renal medulla. Values are arithmetic means \pm SEM ( $\mathrm{n}=6$ mice per group), * $\mathrm{P}<0.05$ vs. control periods; \# $\mathrm{P}<0.05$ vs WT mice with i. r. MSU. WT: C57BL/6J mice; Asc KO: Asc gene knockout mice. 


\section{Kidney Blood Pressure Research}

Kidney Blood Press Res 2016;41:208-221

DOI: 10.1159/000443424

Published online: March 25, 2016

(C) 2016 The Author(s). Published by S. Karger AG, Base www.karger.com/kbr

concentration compared to that in the renal cortex and inner medulla. This may be related to the metabolic feature and its pathological susceptibility to chronic inflammation and fibrosis. It has been reported that the renal medulla undergoes broad shifts in osmolality related to the renal concentrating and diluting mechanism [34]. This section has been considered the most sensitive to apoptosis or oxidative stress and renal interstitial fibrosis [35, 36], which may be associated with its high abundant expression of inflammasome molecules, which can lead to inflammasome activation causing sterile inflammation and direct injury effects. It should be noted that recent transcriptome analysis did not show Nlrp3 expression in the mTAL and CTAL form rats [37]. We did not know the reason for such difference between our mouse study and their rat data. The potential reason may be related to the sensitivity of analysis methods and species differences. More studies are needed to dissect the possible differences among species in the future.

Demonstration of Nlrp3 inflammasome molecules in the renal medulla and mTAL led us to wonder whether the activation of this inflammasome plays an important role in the regulation of renal medullary function. To answer this question, we examined the effects of Nlrp3 inflammasome activation on renal MBF and sodium and water excretion in mice by infusion of a classical Nlrp3 inflammasomes stimulator, MSU into the renal medulla. It was surprisingly found that i.r. MSU resulted in significant decrease in MBF and sodium/water excretion even within 10-30 minutes, which was found to be associated with the cleavage of caspase- 1 into its active isoform, resulting in increases in caspase- 1 activity and IL-1 $\beta$ production. All these effects induced by MSU were abolished by caspase- 1 inhibitor, AcYVAD-CMK. These results suggest that MSU-induced inflammasome activation may produce vasoconstriction in the renal medulla and exerts anti-natriuretic action, which may not be dependent upon classical inflammatory response, but rather due to the direct action of possible products of inflammasome activation during MSU stimulation. It should be noted that reduction of urinary sodium excretion induced by MSU was more profound than that in $\mathrm{MBF}$, indicating that the effects of MSU on the renal function are not only through the action of inflammasome activation on renal medullary blood vessels, but also through some effects on renal tubular reabsorption function [38-41]. In addition, it is interesting that urinary potassium excretion was not changed by this inflammasome activator, which may indicate that Nlrp3 inflammasome product induced by MSU, even though produced in mTAL mainly, may possibly work on collecting ducts to alter their function. Further studies will be needed to clarify how Nlrp3 inflammasome products work to regulate renal function.

Although uric acid has been reported to contribute to the development of renal diseases and thereby may cause hypertension $[22,42]$, the mechanisms by which uric acid induces renal dysfunction remain poorly understood. Our results for the first time indicate that uric acid or its isoforms may result in renal dysfunction through alterations of renal MBF and renal tubular function through Nlrp3 inflammasomes activation. This action may not relate to the classical inflammatory responses, but may be attributable to the direct effect of Nlrp3 inflammasome products such as IL-1 $\beta$. In this regard, some previous studies indeed reported that IL-1 $\beta$ not only as a pro-inflammatory cytokine enhances fibronectin production and disrupts interstitial extracellular matrix on proximal tubular cells $[43,44]$ and renal glomerular or interstitial fibrosis [45], but also directly works on the regulation of $\mathrm{Na}^{+}-\mathrm{K}^{+}-2 \mathrm{Cl}^{-}(\mathrm{NKCC})$ co-transporter in epithelia $[46,47]$, resulting in disturbance of renal excretory function.

To further confirm the involvement of Nlrp3 inflammasome in MSU-induced reduction of renal MBF and renal sodium/water excretion, we performed additional experiments using both Nlrp3 and Asc gene knockout mice. We found that in both Nlrp3 and Asc gene knockout mice, i.r. MSU failed to produce any reduction of renal medullary blood flow and sodium/water excretion compared to their wild type littermates. Correspondingly, there was no activation of Nlrp3 inflammasomes in renal medullary tissue in these knockout mice receiving i.r. MSU. 


\section{Kidney Blood Pressure Research}

It is clear that the reduction of renal medullary blood flow and excretory function induced by infusion of MSU is associated with Nlrp3 inflammasome activation. Although there are reports that Nlrp3 or Asc gene knockout protects the kidney from renal ischemic injury $[48,49]$ and prevents hyperhomocysteinemia-induced glomerular sclerosis $[8,18]$, to our knowledge, the findings from the present study are the first report indicating that Nlrp3 inflammasome may serve as an important mechanism regulating renal medullary blood flow and sodium/water excretion and thereby may participate in the control of arterial blood pressure. This medullary mechanism of Nlrp3 inflammasome activation may be important for understanding of uric acid-induced hypertension [22, 23, 42, 50]. In addition, targeting Nlrp3 inflammasome is a potential novel strategy for development of antihypertensive therapy during different diseases related to metabolic disorders, which may activate this inflammasome as a critical pathogenic mechanism.

\section{Conclusions}

The present study characterized the Nlrp3 inflammasome in the mouse kidney and demonstrated the high abundance of this inflammasome in the renal medulla compared to other kidney regions, and mTAL was found to be a major nephron segment with Nlrp3 inflammasome activity under normal and pathological conditions. Inhibition of Nlrp3 inflammasome activation or deletion of inflammasome genes blocked Nlrp3 inflammasome activation stimulated by MSU in the renal medulla. It is suggested that renal medullary Nlrp3 inflammasomes are a critical intracellular regulatory mechanism of renal medullary function, which may play an important role in the control of sodium excretion and arterial blood pressure.

\section{Disclosure Statement}

The authors confirm that there are no conflicts of interest.

\section{Acknowledgement}

This study was supported by grants from the National Institute of Health (DK054927, HL057244, HL075316 and HL091464 to PL and DK104031 to KB).

\section{References}

1 Mariathasan S, Newton K, Monack DM, Vucic D, French DM, Lee WP, Roose-Girma M, Erickson S, Dixit VM: Differential activation of the inflammasome by caspase-1 adaptors asc and ipaf. Nature 2004;430:213-218.

2 Duewell P, Kono H, Rayner KJ, Sirois CM, Vladimer G, Bauernfeind FG, Abela GS, Franchi L, Nunez G, Schnurr M, Espevik T, Lien E, Fitzgerald KA, Rock KL, Moore KJ, Wright SD, Hornung V, Latz E: Nlrp3 inflammasomes are required for atherogenesis and activated by cholesterol crystals. Nature 2010;464:1357-1361.

3 Li X, Zhang Y, Xia M, Gulbins E, Boini KM, Li PL: Activation of nlrp3 inflammasomes enhances macrophage lipid-deposition and migration: Implication of a novel role of inflammasome in atherogenesis. PLoS One 2014;9:e87552.

4 Xiao H, Lu M, Lin TY, Chen Z, Chen G, Wang WC, Marin T, Shentu TP, Wen L, Gongol B, Sun W, Liang X, Chen J, Huang HD, Pedra JH, Johnson DA, Shyy JY: Sterol regulatory element binding protein 2 activation of nlrp3 inflammasome in endothelium mediates hemodynamic-induced atherosclerosis susceptibility. Circulation 2013;128:632-642.

5 Xia M, Boini KM, Abais JM, Xu M, Zhang Y, Li PL: Endothelial nlrp3 inflammasome activation and enhanced neointima formation in mice by adipokine visfatin. Am J Pathol 2014;184:1617-1628. 


\section{Kidney \\ Blood Pressure Research}

6 Tan MS, Yu JT, Jiang T, Zhu XC, Tan L: The nlrp3 inflammasome in alzheimer's disease. Mol Neurobiol 2013;48:875-882.

7 Vandanmagsar B, Youm YH, Ravussin A, Galgani JE, Stadler K, Mynatt RL, Ravussin E, Stephens JM, Dixit VD: The nlrp3 inflammasome instigates obesity-induced inflammation and insulin resistance. Nat Med 2011;17:179-188.

8 Boini KM, Xia M, Abais JM, Li G, Pitzer AL, Gehr TW, Zhang Y, Li PL: Activation of inflammasomes in podocyte injury of mice on the high fat diet: Effects of asc gene deletion and silencing. Biochim Biophys Acta 2014;1843:836-845.

9 Masters SL, Dunne A, Subramanian SL, Hull RL, Tannahill GM, Sharp FA, Becker C, Franchi L, Yoshihara E, Chen Z, Mullooly N, Mielke LA, Harris J, Coll RC, Mills KH, Mok KH, Newsholme P, Nunez G, Yodoi J, Kahn SE, Lavelle EC, O'Neill LA: Activation of the nlrp3 inflammasome by islet amyloid polypeptide provides a mechanism for enhanced il-1beta in type 2 diabetes. Nat Immunol 2010;11:897-904.

10 Lee HM, Kim JJ, Kim HJ, Shong M, Ku BJ, Jo EK: Upregulated nlrp3 inflammasome activation in patients with type 2 diabetes. Diabetes 2013;62:194-204.

11 Martinon F, Petrilli V, Mayor A, Tardivel A, Tschopp J: Gout-associated uric acid crystals activate the nalp3 inflammasome. Nature 2006;440:237-241.

12 Cassel SL, Eisenbarth SC, Iyer SS, Sadler JJ, Colegio OR, Tephly LA, Carter AB, Rothman PB, Flavell RA, Sutterwala FS: The nalp3 inflammasome is essential for the development of silicosis. Proc Natl Acad Sci USA 2008;105:9035-9040.

13 Imaeda AB, Watanabe A, Sohail MA, Mahmood S, Mohamadnejad M, Sutterwala FS, Flavell RA, Mehal WZ: Acetaminophen-induced hepatotoxicity in mice is dependent on tlr9 and the nalp3 inflammasome. J Clin Invest 2009;119:305-314.

14 Vilaysane A, Chun J, Seamone ME, Wang W, Chin R, Hirota S, Li Y, Clark SA, Tschopp J, Trpkov K, Hemmelgarn BR, Beck PL, Muruve DA: The nlrp3 inflammasome promotes renal inflammation and contributes to ckd. J Am Soc Nephrol 2010;21:1732-1744.

15 Wang J, Long Q Zhang W, Chen N: Protective effects of exogenous interleukin 18-binding protein in a rat model of acute renal ischemia-reperfusion injury. Shock 2012;37:333-340.

16 Anders HJ, Muruve DA: The inflammasomes in kidney disease. J Am Soc Nephrol 2011;22:1007-1018.

17 Deplano S, Cook HT, Russell R, Franchi L, Schneiter S, Bhangal G, Unwin RJ, Pusey CD, Tam FW, Behmoaras $\mathrm{J}$ : P2x7 receptor-mediated nlrp3-inflammasome activation is a genetic determinant of macrophagedependent crescentic glomerulonephritis. J Leukoc Biol 2013;93:127-134.

18 Zhang C, Boini KM, Xia M, Abais JM, Li X, Liu Q, Li PL: Activation of nod-like receptor protein 3 inflammasomes turns on podocyte injury and glomerular sclerosis in hyperhomocysteinemia. Hypertension 2012;60:154-162.

19 Abais JM, Zhang C, Xia M, Liu Q Gehr TW, Boini KM, Li PL: Nadph oxidase-mediated triggering of inflammasome activation in mouse podocytes and glomeruli during hyperhomocysteinemia. Antioxid Redox Signal 2013;18:1537-1548.

20 Mulay SR, Kulkarni OP, Rupanagudi KV, Migliorini A, Darisipudi MN, Vilaysane A, Muruve D, Shi Y, Munro F, Liapis H, Anders HJ: Calcium oxalate crystals induce renal inflammation by nlrp3-mediated il-1beta secretion. J Clin Invest 2013;123:236-246.

21 Kurts C: A crystal-clear mechanism of chronic kidney disease. Kidney Int 2013;84:859-861.

22 Johnson RJ, Nakagawa T, Jalal D, Sanchez-Lozada LG, Kang DH, Ritz E: Uric acid and chronic kidney disease: Which is chasing which? Nephrol Dial Transplant 2013;28:2221-2228.

23 Johnson RJ, Kivlighn SD, Kim YG, Suga S, Fogo AB: Reappraisal of the pathogenesis and consequences of hyperuricemia in hypertension, cardiovascular disease, and renal disease. Am J Kidney Dis 1999;33:225234.

24 Martinon F, Tschopp J: Inflammatory caspases: Linking an intracellular innate immune system to autoinflammatory diseases. Cell 2004;117:561-574.

25 Cervenka L, Mitchell KD, Navar LG: Renal function in mice: Effects of volume expansion and angiotensin II. J Am Soc Nephrol 1999;10:2631-2636.

26 Mattson DL, Meister CJ: Renal cortical and medullary blood flow responses to l-name and ang ii in wild-type, nnos null mutant, and enos null mutant mice. Am J Physiol Regul Integr Comp Physiol 2005;289:R991-997. 


\section{Kidney \\ Blood Pressure Research}

Xia/Abais/Koka/Meng/Gehr/Boini/Li: NLRP3 inflammasome activation in kidney

27 Xia M, Li PL, Li N: Telemetric signal-driven servocontrol of renal perfusion pressure in acute and chronic rat experiments. Am J Physiol Regul Integr Comp Physiol 2008;295:R1494-1501.

28 Zhu Q, Xia M, Wang Z, Li PL, Li N: A novel lipid natriuretic factor in the renal medulla: Sphingosine-1phosphate. Am J Physiol Renal Physiol 2011;301:F35-F41.

29 Ritter JK, Li C, Xia M, Poklis JL, Lichtman AH, Abdullah RA, Dewey WL, Li PL: Production and actions of the anandamide metabolite prostamide E2 in the renal medulla. J Pharmacol Exp Ther 2012;342:770-779.

30 Zou AP, Yang ZZ, Li PL, Cowley AJ: Oxygen-dependent expression of hypoxia-inducible factor-1alpha in renal medullary cells of rats. Physiol Genomics 2001;6:159-168.

31 Schafer JA, Watkins ML, Li L, Herter P, Haxelmans S, Schlatter E: A simplified method for isolation of large numbers of defined nephron segments. Am J Physiol 1997;273:F650-F657.

32 Li N, Yi FX, Spurrier JL, Bobrowitz CA, Zou AP: Production of superoxide through nadh oxidase in thick ascending limb of henle's loop in rat kidney. Am J Physiol Renal Physiol 2002;282:F1111-F1119.

33 Shigeoka AA, Mueller JL, Kambo A, Mathison JC, King AJ, Hall WF, Correia Jda S, Ulevitch RJ, Hoffman HM, McKay DB: An inflammasome-independent role for epithelial-expressed nlrp3 in renal ischemiareperfusion injury. J Immunol 2010;185:6277-6285.

34 Beck FX, Burger-Kentischer A, Muller E: Cellular response to osmotic stress in the renal medulla. Pflugers Arch 1998;436:814-827.

35 Horio M, Ito A, Matsuoka Y, Moriyama T, Orita Y, Takenaka M, Imai E: Apoptosis induced by hypertonicity in madin darley canine kidney cells: Protective effect of betaine. Nephrol Dial Transplant 2001;16:483-490.

36 Li N, Chen L, Yi F, Xia M, Li PL: Salt-sensitive hypertension induced by decoy of transcription factor hypoxiainducible factor-1alpha in the renal medulla. Circ Res 2008;102:1101-1108.

37 Lee JW, Chou CL, Knepper MA: Deep sequencing in microdissected renal tubules identifies nephron segment-specific transcriptomes. J Am Soc Nephrol 2015;26:2669-2677.

38 Kang DH, Park SK, Lee IK, Johnson RJ: Uric acid-induced c-reactive protein expression: Implication on cell proliferation and nitric oxide production of human vascular cells. J Am Soc Nephrol 2005;16:3553-3562.

39 Khosla UM, Zharikov S, Finch JL, Nakagawa T, Roncal C, Mu W, Krotova K, Block ER, Prabhakar S, Johnson RJ: Hyperuricemia induces endothelial dysfunction. Kidney Int 2005;67:1739-1742.

40 Simao AN, Lozovoy MA, Dichi I: The uric acid metabolism pathway as a therapeutic target in hyperuricemia related to metabolic syndrome. Expert Opin Ther Targets 2012;16:1175-1187.

41 Turner CM, Arulkumaran N, Singer M, Unwin RJ, Tam FW: Is the inflammasome a potential therapeutic target in renal disease? BMC Nephrol 2014;15:21.

42 Nakagawa T, Kang DH, Feig D, Sanchez-Lozada LG, Srinivas TR, Sautin Y, Ejaz AA, Segal M, Johnson RJ: Unearthing uric acid: An ancient factor with recently found significance in renal and cardiovascular disease. Kidney Int 2006;69:1722-1725.

43 Vesey DA, Cheung CW, Cuttle L, Endre ZA, Gobe G, Johnson DW: Interleukin-1beta induces human proximal tubule cell injury, alpha-smooth muscle actin expression and fibronectin production. Kidney Int 2002;62:31-40.

44 Nee LE, McMorrow T, Campbell E, Slattery C, Ryan MP: TNF-alpha and IL-1beta-mediated regulation of MMP-9 and TIMP-1 in renal proximal tubular cells. Kidney Int 2004;66:1376-1386.

45 Nickeleit V, Mihatsch MJ: Uric acid nephropathy and end-stage renal disease--review of a non-disease. Nephrol Dial Transplant 1997;12:1832-1838.

46 Kim SJ, Choi JY, Son EJ, Namkung W, Lee MG, Yoon JH: Interleukin-1beta upregulates Na+-K+-2Clcotransporter in human middle ear epithelia. J Cell Biochem 2007;101:576-586.

47 Lu K-T, Wu C-Y, Yang Y-L: Na-K-2Cl cotransporters contributes to IL-1-induced neuronal damage during traumatic brain injury. J Cereb Blood Flow Metab 2005;25:S265.

48 Kim HJ, Lee DW, Ravichandran K, D OK, Akcay A, Nguyen Q, He Z, Jani A, Ljubanovic D, Edelstein CL: Nlrp3 inflammasome knockout mice are protected against ischemic but not cisplatin-induced acute kidney injury. J Pharmacol Exp Ther 2013;346:465-472.

49 Kawaguchi M, Takahashi M, Hata T, Kashima Y, Usui F, Morimoto H, Izawa A, Takahashi Y, Masumoto J, Koyama J, Hongo M, Noda T, Nakayama J, Sagara J, Taniguchi S, Ikeda U: Inflammasome activation of cardiac fibroblasts is essential for myocardial ischemia/reperfusion injury. Circulation 2011;123:594-604.

50 Ejaz AA, Mu W, Kang DH, Roncal C, Sautin YY, Henderson G, Tabah-Fisch I, Keller B, Beaver TM, Nakagawa T, Johnson RJ: Could uric acid have a role in acute renal failure? Clin J Am Soc Nephrol 2007;2:16-21. 